\title{
Oligomer of Indolizine Derivative and Its pH Sensitive Behavior
}

\author{
Nagatoshi NishiwaKi, Kiyonori Furuta, Mitsuo Komatsu, \\ and Yoshiki OHSHIRO* \\ Department of Applied Chemistry, Faculty of Engineering, Osaka University, \\ Yamadaoka 2-1, Suita, Osaka 565, Japan
}

(Received October 11, 1990)

\begin{abstract}
The 1-( $\alpha$-alkoxybenzyl)indolizine derivative synthesized from 2-phenylethynylpyridine readily oligomerized in chloroform at room temperature. The structure of the oligomer was determined by spectral data as well as comparison with those of the dimer and the trimer which were isolated in the earlier stage of the reaction. Thus oligomer of indolizine was synthesized for the first time. It was also found that the oligomerization was catalyzed by acid and that chloroform was the most suitable solvent for the present reaction. The obtained oligomer exhibited bluish green color and turned to yellowish brown under basic conditions. This $\mathrm{pH}$ sensitive behavior was observed on the UV-VIS spectra and the change of color showed reversibility.

KEY WORDS Indolizine Oligomer / Acidic Oligomerization / $\mathrm{pH}$ Sensitive Character / Reversible Colorization / Functional Dye /
\end{abstract}

In the previous paper, ${ }^{1}$ we reported the synthesis of indolizine derivatives by the cycloaddition of 2-phenylethynylpyridine (1) and dimethyl acetylenedicarboxylate in the presence of proton source such as alcohols or dimethyl malonate. When the hindered proton sources, $t$-butanol and dimethyl malonate, were used, 2,3-bis(methoxycarbonyl)indolizines $\mathbf{2}$ were obtained. While the less hindered proton sources such as methanol, ethanol, and isopropanol, were employed, demethoxycarbonylation at the 3-position proceeded to give 2-methoxycarbonylindolizines 3. Polyfunctionalized indolizines are used for various purposes, ${ }^{2,3}$ such as drugs and light screening agents in photographic emulsions. Especially, indolizine derivatives are extensively used as dyes. $^{4-8}$

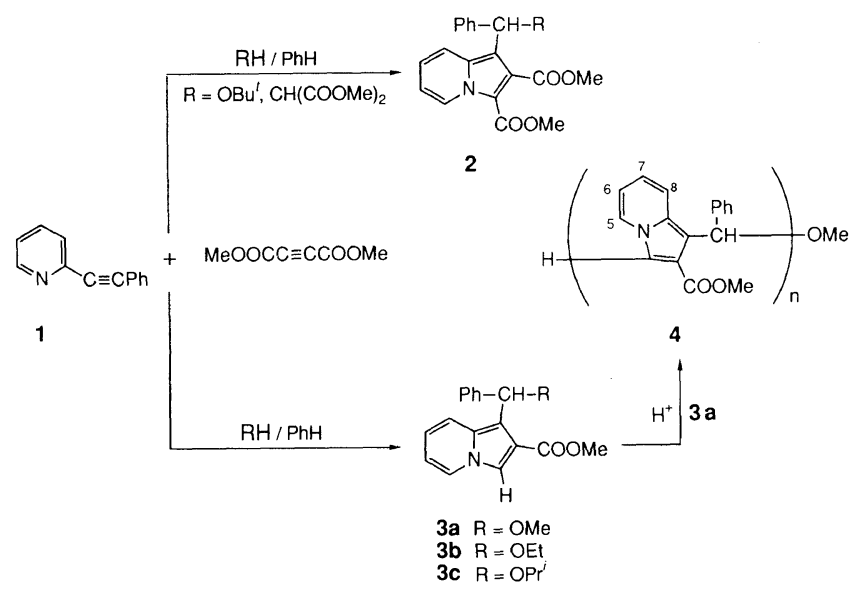


The monomethoxycarbonyl derivatives 3 was found to be unstable toward acid and readily transformed to the bluish green oligomer 4 . Oligomers or polymers of indolizine derivatives are hitherto unknown, and there has been only one example of polymer-supported indolizine dye. ${ }^{9}$ Hence, the present oligomer 4 is interesting in points of the chemical and physical properties. The oligomer 4 is $\mathrm{pH}$ sensitive and turned to yellowish brown under basic conditions. Since it is necessary to change color effectively by $\mathrm{pH}$ for functional dyes such as $\mathrm{pH}$ sensors and pressure-sensitive or thermosensitive recording materials, the indolizine 3 and its oligomer 4 are expected to become dyes mentioned above.

\section{EXPERIMENTAL}

\section{Materials and Monomers}

Commercially available tetrahydrofuran (THF) and chloroform were used without purification and chloroform contains $1 \times 10^{-4}$ $\%$ hydrochloric acid. Dimethyl acetylenedicarboxylate (DMAD), methanol, and benzene were purified by distillation. 2-Phenylethynylpyridine was prepared according to our method. ${ }^{10}$

\section{1-( $\alpha$-Methoxybenzyl)-2-methoxycarbonylindoli- zine (3a)}

To a benzene solution $(10 \mathrm{ml})$ of 2phenylethynylpyridine (1) (179 mg, $1 \mathrm{mmol})$, methanol $(0.81 \mathrm{ml}, 20 \mathrm{mmol})$ and DMAD $(0.25 \mathrm{ml}, 2 \mathrm{mmol})$ were added and stirred at room temperature for one day. The mixture was concentrated and chromatographed $\left(\mathrm{SiO}_{2}\right.$-hexane $\left./ \mathrm{AcOEt}=95 / 5\right)$ to isolate 3a ( $251 \mathrm{mg}, 0.85 \mathrm{mmol})$ in $85 \%$ yield. Pale yellow oil, IR (neat $/ \mathrm{cm}^{-1}$ ) $1750(\mathrm{C}=\mathrm{O}) ;{ }^{1} \mathrm{H}$ NMR $\left(90 \mathrm{MHz}, \mathrm{C}_{6} \mathrm{D}_{6}\right) \delta 2.95(\mathrm{~s}, 3 \mathrm{H}, \mathrm{MeO}), 3.13(\mathrm{~s}$, $3 \mathrm{H}, \mathrm{COOMe}), 5.46(\mathrm{~s}, 1 \mathrm{H}, \mathrm{CH}), 6.1-6.6(\mathrm{~m}$, $2 \mathrm{H}, \mathrm{H}-6,-7), 6.54$ (s, 1H, H-3), 7.0-7.5 (m, $4 \mathrm{H}, \mathrm{H}-8,-m,-p), 7.81(\mathrm{dd}, J=8.1,1.2 \mathrm{~Hz}, 2 \mathrm{H}$, $\mathrm{H}-\mathrm{o}$ ), and $8.80 \mathrm{ppm}(\mathrm{d}, J=7.1 \mathrm{~Hz}, 1 \mathrm{H}, \mathrm{H}-5)$; MS (EI) $m / z 295\left(\mathrm{M}^{+}, 12\right), 236\left(\mathrm{M}^{+}-\mathrm{COOMe}\right.$,
100); Anal. Calcd. for $\mathrm{C}_{18} \mathrm{H}_{17} \mathrm{NO}_{3}$ : C, $73.20 \%$; $\mathrm{H}, 5.80 \%$; N, $4.74 \%$; O, $16.25 \%$. Found: C, $72.87 \% ; \mathrm{H}, 5.87 \%$; N, $4.69 \%$.

Other indolizine derivatives $\mathbf{2}$ and $\mathbf{3 b}$, $\mathbf{c}$ were prepared by the similar methods.

\section{Oligomerization of Indolizines $\mathbf{3}$}

A solution of indolizine $3 \mathbf{a}(50 \mathrm{mg}, 0.7 \mathrm{mmol})$ in chloroform $(15 \mathrm{ml})$ was stirred at room temperature for 1 day. The solution was concentrated in vacuo and the residual solid was washed with hexane to give the oligomer 4 quantitatively. Bluish green solid; $\mathrm{mp}$ $>300^{\circ} \mathrm{C}$; IR $\left(\mathrm{KBr} / \mathrm{cm}^{-1}\right) 1740(\mathrm{C}=\mathrm{O}) ;{ }^{1} \mathrm{H}$ NMR $\left(90 \mathrm{MHz}, \mathrm{CDCl}_{3}\right) \delta 2.8-3.5$ (br., $3 \mathrm{H}$, COOMe), 5.4-5.7 (br., 1H, CㅂPh), 5.8-6.6 (br., 3H, H-6, -7, -8), 6.7-7.6 (br., 5H, Ph), and 7.6-8.1 ppm (br., 1H, H-5). The oligomer 4 was not burnt completely even when excessive oxygen was used and satisfactory analytical data were not obtained.

\section{Oligomerization under Basic Conditions}

Chloroform was washed with saturated $\mathrm{NaHCO}_{3}$ aq. $(30 \mathrm{ml} \times 2)$ prior to the reaction. A solution of $3 \mathbf{a}(50 \mathrm{mg}, 0.7 \mathrm{mmol})$ in base-washed chloroform $(15 \mathrm{ml})$ was stirred in the presence of $\mathrm{NaHCO}_{3}(590 \mathrm{mg}, 7 \mathrm{mmol})$ at room temperature for 5 days. The solution was concentrated and chromatographed $\left(\mathrm{SiO}_{2}\right)$ to give a mixture of dimer, trimer, tetramer and so on. However $50 \%$ of the starting material ( $25 \mathrm{mg}, 0.35 \mathrm{mmol}$ ) was recovered.

\section{Isolation of Dimer $\mathbf{5}$ and Trimer of $\mathbf{3 a}$}

A solution of $\mathbf{3 a}(50 \mathrm{mg}, 0.7 \mathrm{mmol})$ in chloroform $(15 \mathrm{ml})$ was stirred at room temperature for $1 \mathrm{~h}$. The solution was concentrated and chromatographed $\left(\mathrm{SiO}_{2}\right)$ to give dimer 5 (10 mg, $0.11 \mathrm{mmol})$, trimer $(7 \mathrm{mg}$, $0.07 \mathrm{mmol})$, and tetramer $(1 \mathrm{mg}, 0.01 \mathrm{mmol})$ in $15 \%, 10 \%$, and $2 \%$ yields, respectively and $70 \%$ of monomer $(35 \mathrm{mg}, 0.49 \mathrm{mmol})$ was recovered. 


\section{The Dimer 5}

Brownish yellow plates; eluted with hexane $/ \mathrm{AcOEt}=90 / 10 ; \mathrm{mp} 41-44^{\circ} \mathrm{C}$; IR (neat/ $\left.\mathrm{cm}^{-1}\right) 1740(\mathrm{C}=\mathrm{O})$; The dimer was found to be a mixture of the isomers $(73 / 27)$ by ${ }^{1} \mathrm{H}$ NMR. ${ }^{1} \mathrm{H}$ NMR for the major isomer $\left(270 \mathrm{MHz}, \mathrm{C}_{6} \mathrm{D}_{6}\right) \delta 2.97$ (s, 3H, OMe), 3.05 (s, $\left.3 \mathrm{H}, \mathrm{COOMe}^{\mathrm{b}}\right), 3.11\left(\mathrm{~s}, 3 \mathrm{H}, \mathrm{COOMe}^{\mathrm{a}}\right), 5.10(\mathrm{~s}$, $\left.1 \mathrm{H}, \mathrm{H}^{\mathrm{a}}\right), 6.0-6.4\left(\mathrm{~m}, 5 \mathrm{H}, \mathrm{H}-6,-7,-6^{\prime},-7^{\prime},-8^{\prime}\right)$, $6.33\left(\mathrm{~s}, 1 \mathrm{H}, \mathrm{H}^{\mathrm{b}}\right), 6.60\left(\mathrm{~s}, 1 \mathrm{H}, \mathrm{H}-3^{\prime}\right), 7.0-7.5$ $\left(\mathrm{m}, 9 \mathrm{H}, \mathrm{Ph}^{\mathrm{b}}, \mathrm{H}-8,-m,-p\right), 7.74$ (dd, $J=7.3$, $1.6 \mathrm{~Hz}, 2 \mathrm{H}, \mathrm{H}-o$ ), 8.24 (dd, $J=6.2,1.1 \mathrm{~Hz}, 1 \mathrm{H}$, $\mathrm{H}-5$ ), and $8.72 \mathrm{ppm}(\mathrm{dd}, J=5.9,1.1 \mathrm{~Hz}, 1 \mathrm{H}$, $\left.\mathrm{H}-5^{\prime}\right) ;{ }^{1} \mathrm{H}$ NMR for the minor isomer $\left(270 \mathrm{MHz}, \mathrm{C}_{6} \mathrm{D}_{6}\right) \delta 2.877$ (s, 3H, OMe), 2.884 (s, 3H, COOMe ${ }^{\mathrm{b}}$ ), 3.11 (s, 3H, COOMe $\left.{ }^{\mathrm{a}}\right), 5.21$ $\left(\mathrm{s}, 1 \mathrm{H}, \mathrm{H}^{\mathrm{a}}\right), 6.0-6.4\left(\mathrm{~m}, 5 \mathrm{H}, \mathrm{H}-6,-7,-6^{\prime},-7^{\prime}\right.$, $\left.-8^{\prime}\right), 6.37\left(\mathrm{~s}, 1 \mathrm{H}, \mathrm{H}^{\mathrm{b}}\right), 6.68\left(\mathrm{~s}, 1 \mathrm{H}, \mathrm{H}-3^{\prime}\right), 7.0-7.5$ (m, 9H, $\left.\mathrm{Ph}^{\mathrm{b}}, \mathrm{H}-8,-m,-p\right), 7.82$ (dd, $J=7.3$, $1.6 \mathrm{~Hz}, 2 \mathrm{H}, \mathrm{H}-o), 8.35$ (dd, $J=6.2,1.1 \mathrm{~Hz}, 1 \mathrm{H}$, $\mathrm{H}-5$ ), and $8.84 \mathrm{ppm}$ (dd, $J=5.9,1.1 \mathrm{~Hz}, 1 \mathrm{H}$, H-5'); MS (EI) m/z $558\left(\mathrm{M}^{+}, 11\right), 499\left(\mathrm{M}^{+}-\right.$ COOMe, 100); HRMS Calcd for $\mathrm{C}_{35} \mathrm{H}_{30} \mathrm{~N}_{2} \mathrm{O}_{5}$ $\left(\mathrm{M}^{+}\right)$: 558.2156, Found: 558.2158.

\section{The Trimer of 3a}

Yellowish brown plates; eluted with hexane $/ \mathrm{AcOEt}=80 / 20 ; \mathrm{mp} 111-113^{\circ} \mathrm{C}$; IR (neat/ $\left.\mathrm{cm}^{-1}\right) 1740(\mathrm{C}=\mathrm{O}) ;{ }^{1} \mathrm{H} \mathrm{NMR}\left(90 \mathrm{MHz}, \mathrm{C}_{6} \mathrm{D}_{6}\right)$ $\delta 2.8-3.2(\mathrm{~m}, 12 \mathrm{H}, \mathrm{OMe}, \mathrm{COOMe} \times 3), 5.13$ (s, $1 \mathrm{H}, \mathrm{C} \underline{\mathrm{HOMe}}), 5.8-6.6\left(\mathrm{~m}, 12 \mathrm{H}, \mathrm{H}^{\mathrm{b}}, \mathrm{H}^{\mathrm{c}}\right.$,

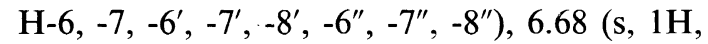
$\left.\mathrm{H}-3^{\prime \prime}\right), 6.8-7.2\left(\mathrm{~m}, 14 \mathrm{H}, \mathrm{Ph}^{\mathrm{b}}, \mathrm{Ph}^{\mathrm{c}}, \mathrm{H}-m,-p\right)$, 7.7-7.9 (m, 2H, H-o), $8.10(\mathrm{dm}, J=6.1 \mathrm{~Hz}$, $\left.1 \mathrm{H}, \mathrm{H}-5^{\prime}\right), 8.38(\mathrm{dm}, J=6.1 \mathrm{~Hz}, 1 \mathrm{H}, \mathrm{H}-5)$, and $8.76 \mathrm{ppm}$ (dm, $\left.J=6.1 \mathrm{~Hz}, 1 \mathrm{H}, \mathrm{H}-5^{\prime \prime}\right)$; MS (EI) $m / z 821\left(\mathrm{M}^{+}, 71\right), 762\left(\mathrm{M}^{+}-\mathrm{COOMe}, 100\right)$.

\section{Transformation of $\mathbf{4}$ to Yellowish Brown Solid}

To a solution of $4(20 \mathrm{mg})$ in THF $(20 \mathrm{ml})$, ammonia gas was bubbled for $5 \mathrm{~min}$. The solution was then bubbled with nitrogen gas for $30 \mathrm{~min}$ to purge excess ammonia and concentrated to give the hygroscopic yellowish brown solid.; IR $\left(\mathrm{KBr} / \mathrm{cm}^{-1}\right) 1730(\mathrm{C}=\mathrm{O})$.

\section{Observation of $p H$ Sensitive Behavior on UV-VIS Spectra}

A dioxane solution of $4(1.33 \mathrm{~g} / \mathrm{l})$ and $0.5 \mathrm{M}$ buffer solution $\left(\mathrm{H}_{3} \mathrm{BO}_{3}-\mathrm{NaOH}\right)$ which has prescribed $\mathrm{pH}$ value were mixed $(1 / 10)$ and subjected to measurement on UV-VIS spectrometer.

\section{Measurement}

The molecular weight distribution of the oligomer 4 was determined by gel permeation chromatography (GPC) using Toyo Soda HLC CP8000 with Cosmosil 5GPC-100 and 5GPC300 (Toyo Soda), and UV detector operating at $254 \mathrm{~nm}$ with THF as an eluent.

Melting points are uncorrected. Mass spectra were obtained using a Shimadzu GCMSQP2000 mass spectrometer and high resolution mass spectrum (HRMS) was recorded with a JEOL JMS-DX303 mass spectrometer. IR spectra were recorded on a Hitachi 270-30 infrared spectrometer and ${ }^{1} \mathrm{H}$ NMR spectra were measured on a JEOL FT-NMR JMN FX90Q spectrometer at $90 \mathrm{MHz}$ or a JEOL FT-NMR GSX spectrometer at $270 \mathrm{MHz}$ with TMS as an internal standard. Elemental analyses were performed on Yanagimoto $\mathrm{CHN}$ Corder Mt-2. UV-VIS spectra were recorded on a Shimadzu UV-265 spectrophotometer equipped with temperature-controlled cell holder, Shimadzu TCC-260. Values of $\mathrm{pH}$ were determined on a Horiba $\mathrm{pH}$ meter F-8.

\section{RESULTS AND DISCUSSION}

\section{Oligomerization of Indolizine $\mathbf{3 a}$}

The indolizine $3 \mathbf{a}(50 \mathrm{mg})$ was readily oligomerized by stirring in commercially available chloroform $(15 \mathrm{ml})$ at room temperature to give the oligomer 4 quantitatively. The oligomer 4 was easily soluble in $\mathrm{CHCl}_{3}$, $\mathrm{CH}_{2} \mathrm{Cl}_{2}$, THF and 1,4-dioxane. The reaction was monitored by thin layer chromatography (TLC) developed with hexane-AcOEt (50:50) and was stopped when the original spot showed no change. After stirring for $0.5 \mathrm{~h}$, the reaction 
mixture turned to bluish green and the reaction completed after 1 day. The rate of oligomerization was influenced by the amount of the solvent. When one third amount of chloroform $(5 \mathrm{ml})$ was used, 3 days were required to complete the reaction because of decrease in the amount of the acid catalyst in the reaction mixture.

Although other monomethoxycarbonylindolizines $\mathbf{3 b}$, 3c oligomerized similarly, bis(methoxycarbonyl) derivatives 2 were comparatively stable against acid and oligomerization did not undergo.

Under basic conditions, this reaction in chloroform was depressed and $50 \%$ of the starting material was recovered even after 5 days. Thus the oligomerization was thought to be catalyzed by hydrochloric acid which was contained in chloroform. The oligomer was also obtained when 3a was stirred in THF containing hydrochloric acid (equimolar to 3a) or silica gel, or in acetic acid. In these cases, longer reaction times than the case with chloroform were needed. Thus chloroform was found to be a suitable solvent containing the catalyst for the present reaction.

\section{Structural Determination of the Oligomer 4}

The weight-average molecular weight of the oligomer 4 was about 1500 using polystyrene as a standard. No cleavage was observed in the methoxycarbonyl group at 2-position by IR spectrum. When the reaction was monitored by ${ }^{1} \mathrm{H}$ NMR, the generation of methanol eliminated during the oligomerization was detected. From these results along with that of other spectral data, the structure of the oligomer was determined as 4. This structure was supported by the comparison with that of the dimer $\mathbf{5}$ or the trimer of $\mathbf{3 a}$ isolated in the earlier stage of the reaction.

The structures of the dimer and the trimer were established by spectral and analytical data. It was confirmed by the mass spectra that each of these was bimolecularly or trimolecularly condensed compound accompanied by elimination of one or two molecules of methanol. The ${ }^{1} \mathrm{H}$ NMR spectra were satisfactorily assigned to the structures and one of the features of the spectra is the signals of the inner protons $\left(\mathrm{H}-5,-6,-8^{\prime}, \mathrm{Ph}^{\mathrm{b}}, \mathrm{COOMe}^{\mathrm{b}}\right)$ of 5 were observed in higher fields than the signals of the outer protons or the corresponding signals of monomer 3a. This observation could be explained by that the indolizine rings are torsionally restrained and the protons at the inside positions are located above the other indolizine ring. The dimer 5 was found to be a mixture of isomers $(73: 27)$ by ${ }^{1} \mathrm{H}$ NMR and the coalesced spectrum was not obtained on a measurement even at $70^{\circ} \mathrm{C} .{ }^{13} \mathrm{C} \mathrm{NMR}$ spectrum was too complicate to be assigned, but the six signals of methoxy carbons were confirmed (at $\delta 51.38,51.44,51.50,51.61$ $(\mathrm{COOMe} \times 4), 56.28,56.51(\mathrm{OMe} \times 2))$.

\section{A Plausible Path of Oligomerization}

Indolizine derivatives are known to have

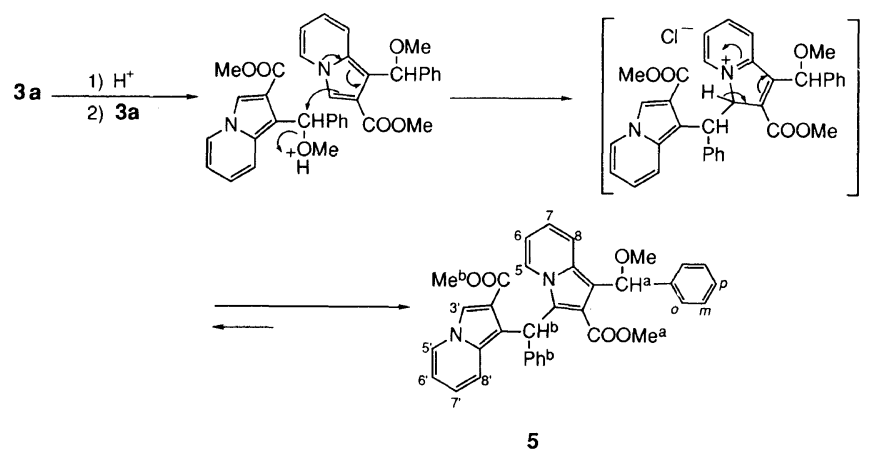



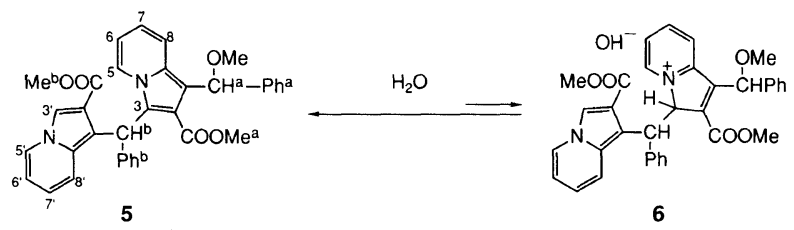

nucleophilicity at 1- and 3-positions. ${ }^{2,3}$ In the present case, the indolizine $\mathbf{3 a}$ activated by protonation was considered to be attacked by the carbon at 3-position of another molecule to produce the dimer $\mathbf{5}$ via the successive aromatization. Repetition of this condensation reaction will reasonably lead to the oligomer 4 under acidic conditions. This path is supported by the generation of methanol during the oligomerization.

\section{pH Sensitive Behavior of 4 Depending on $p H$}

Under basic conditions, the color of the oligomer 4 turned to yellowish brown from bluish green. This transformation was performed with bubbling ammonia gas to a solution of 4 in THF for 5 min. Aqueous $\mathrm{NaOH}$ was also available instead of ammonia to change the color. The solution was concentrated to give the hygroscopic yellowish

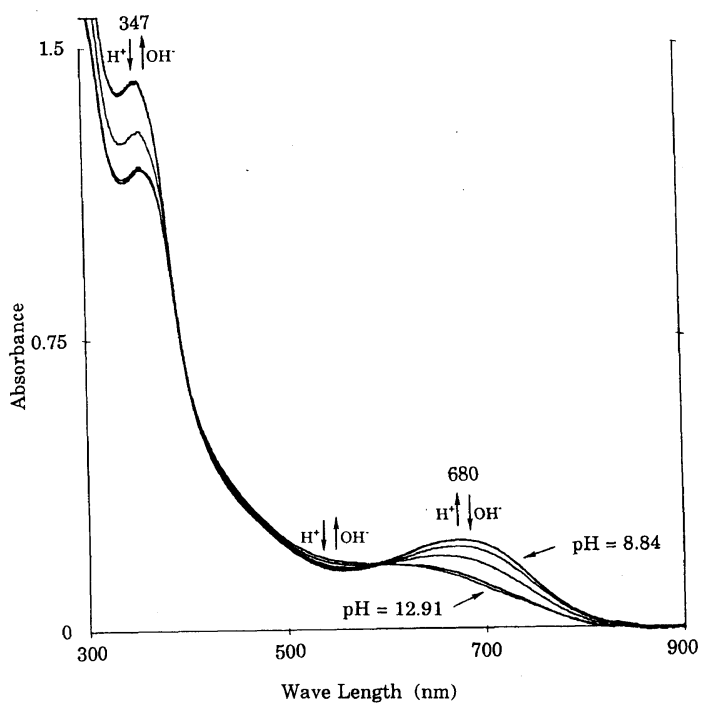

Figure 1. The change of color of the oligomer 4 depending on $\mathrm{pH}$.

brown solid. The compound possessed ester groups whose absorption was shown at $1730 \mathrm{~cm}^{-1}$ in the IR spectrum.

The change of color was clearly observed on the UV-VIS spectra, namely the absorbance decreased at $680 \mathrm{~nm}$ and increased at $347 \mathrm{~nm}$.

On the other hand, the color retruned to bluish green under acidic conditions. This change of color was reversible and its $\mathrm{p} K_{\mathrm{obs}}$ was 11.1 .

The isolated dimer was also colored garadually on standing for several days at room temperature. When this change was monitored by ${ }^{1} \mathrm{H}$ NMR, generation of the signals of the $3 \mathrm{H}$-dimer 6 was observed and $20 \%$ of dimer 5 was transformed to $3 H$-dimer 6 after three weeks. This ${ }^{1} \mathrm{H}$ NMR spectrum of a mixture of 5 and 6 was too complicate to assign all of the signals, but two new doublets $(J=7.2 \mathrm{~Hz})$ at $\delta 3.33$ and $3.70 \mathrm{ppm}$ corresponding to $\mathrm{H}-3$ and $\mathrm{H}^{\mathrm{b}}$ were confimed and the shift of the signal of $\mathrm{H}-5$ (from $\delta 8.24 \mathrm{ppm}$ to $\delta 8.74 \mathrm{ppm}$ ) to lower field was observed.

On the UV-VIS spectra, the absorbance at $660 \mathrm{~nm}$ increased along with this change of color, but the absorption was not observed so clearly as compared with that of the oligomer 4. When the colored dimer was allowed to stand under basic conditions, the weak absorption at $660 \mathrm{~nm}$ faded.

From these results, it is considered that some units of 7 are formed in the oligomer 4 and changed depending on $\mathrm{pH}$.

There seems to be a possibility to apply the

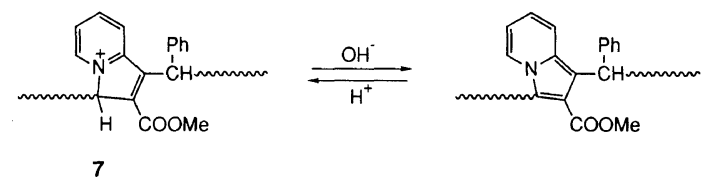


present $\mathrm{pH}$ sensitive material to functional dyes by modification of monomeric indolizine derivatives.

Acknowledgement. This work was partially supported by the Grant-in-Aid for Scientific Reasearch from the Ministry of Education, Science, and Culture of Japan.

\section{REFERENCES}

1. N. Nishiwaki, K. Furuta, M. Komatsu, and Y. Ohshiro, J. Chem. Soc. Chem. Comm., 1151 (1990).

2. W. Flitsch, in "Comprehensive Heterocyclic Chem- istry," Vol. 4, A. R. Katritzky, Ed., Pergamon Press, Oxford, 1984, p 443.

3. F. J. Swinbourne, J. H. Hunt, and G. Klinkert, $A d v$. Heterocycl. Chem., 23, 103 (1978).

4. D. H. Wadsworth, C. H. Weidener, S. L. Bender, and D. J. Beltman, J. Org. Chem., 54, 3660 (1989).

5. J. W. Wheeler, Eur. Pat. Appl., EP 161,789; Chem. Abstr., 104, 170108z (1986).

6. A. R. Katritzky, K. C. Caster, O. Rubio, and O. Schwarz, J. Heterocyclic Chem., 23, 1315 (1986).

7. S. Gunzenhauser and H. Balli, Helv. Chim. Acta, 68, 56 (1985).

8. R. Naef, Dyes Pigm., 4, 101 (1983).

9. C. Holstead, Ger. Offen., 2,122,060; Chem. Abstr., 76, 40240d (1972).

10. N. Nishiwaki, S. Minakata, M. Komatsu, and Y. Ohshiro, Chem. Lett., 773 (1989). 